\title{
Model for Predicting the Transport and Dispersal of Contaminants Incoming with Submarine Groundwater: Case Study for the Southwestern Taiwan Coastal Zone
}

\author{
Konstantin A. Korotenko ${ }^{1}$, Peter O. Zavialov ${ }^{1}$, Ruey-Chy Kao ${ }^{2}$, Chung-Feng Ding ${ }^{2}$ \\ ${ }^{1}$ Shirshov Institute of Oceanology, Russian Academy of Sciences, Moscow, Russia \\ ${ }^{2}$ Tainan Hydraulics Laboratory, National Cheng-Kung University, Tainan, Chinese Taipei \\ Email: kkoroten@yahoo.com
}

Received February 29, 2012; revised March 19, 2012; accepted March 26, 2012

\begin{abstract}
As was recognized recently, the submarine groundwater transports a significant amount of various contaminants into the coastal ocean. An assessment of the impact of intruded pollutants in the coastal ecosystems requires understanding fate of the pollutants and processes of their dispersal in ambient waters. In this paper, we proposed a 3-D coupled ocean circulation/particle-tracking model for predicting the transport and dispersal of pollution-containing groundwater discharged into a coastal environment of the southwestern Taiwan. The particle-tracking model takes currents and turbulent diffusivities predetermined by the ocean circulation model and uses the Lagrangian approach to predict the motion of individual droplets, the sum of which constitutes a contaminant plume in result of discharge of contaminant-rich submarine groundwater. The ocean circulation model was forced by tides and seasonal favorable winds for the southwestern coast of Taiwan. The initialization of the coupled model was set using field data obtained in 2009 on the Pingtung shelf where shallow aquifer seepages were discovered. Several types of numerical experiment scenarios were set up to elucidate the transport and dispersal of conservative and nonconservative (nitrate) contaminants in the shallow coastal zone. The comparison of obtained numerical results with observations performed by other researches was discussed.
\end{abstract}

Keywords: Submarine Groundwater; Coastal Zone; Nitrate; Eulerian-Lagrangian Model; Taiwan

\section{Introduction}

Submarine groundwater discharge (hereinafter SGD) has been recognized as the potentially significant contribution to the coastal ocean [1]. Although not as obvious as river discharge, groundwaters (hereinafter SGs) can also discharge directly into the coastal ocean. Like surface water, groundwater flows downgradient. Therefore, groundwater flows directly into the coastal ocean wherever a coastal aquifer is connected to the sea. Furthermore, artesian aquifers can extend for considerable distances from shore, underneath the continental shelf with discharge to the coastal ocean at their points of outcrop. In some cases, these deeper aquifers may have fractures or other breaches in the overlying confining layers, allowing groundwater to flow into the sea Figure 1(b) schematically illustrates shallow and deep aquifers and processes associates with SGD.

Very importantly, it is now recognized that groundwater discharge may be an important pathway for diffuse pollution to enter the coastal zone where coastal aquifers have become contaminated by septic systems or other pollution sources [2]. Despite SGD contribution in the ocean's water budget is generally small, it represents an important source of nutrients and other contaminants that affect the ecology of the estuaries and coastal fresh water bodies [1,3-7]. There are reports that SGD may also be an important source of alkalinity and carbon to shelf waters [8].

Submarine groundwater coming from coastal aquifers into the coastal ocean carries dissolved contaminants, concentration and type of which considerably varied from region to region. Multiple studies indicate that the concentration of groundwater contaminants increases with increasing housing density and agriculture activity. Expanding residential and commercial near-shore development is leading to increased nutrient inputs to groundwater that eventually migrate into to coastal waters. Severaldecades long research shows that nitrogen inputs via 


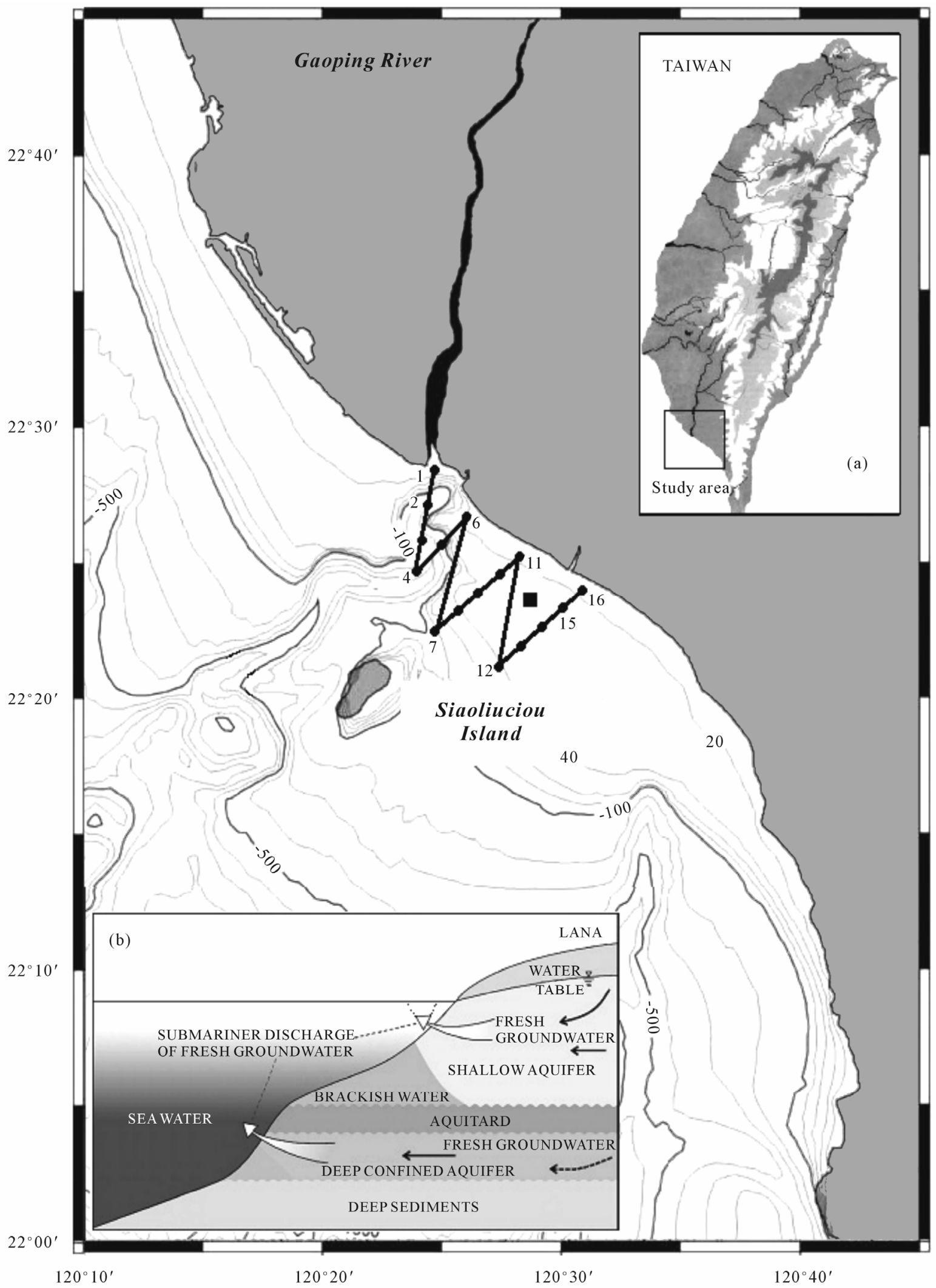

Figure 1. Map of the Pingtung coastal zone showing the bathymetry off southwestern Taiwan and stations of hydrographical observations (marked by solid circles) in the area of the shallow SG well (marked by the solid square). The lower inset (2b) depicts the schematic (no scale) of processes associated with SGD (after [1]). 
non-point sources over large coastline areas cause decline of ecological health and may support harmful algal blooms [9].

In Taiwan, investigations of the offshore discharge of groundwater, for many years, were largely motivated by water resource related issues. As was noted by [10], there were at least two reasons why scientific studies have developed so slowly in this field. First, the SGD process is inherently very difficult to measure and monitor, which tended to discourage serious investigations. Nearshore seepages around Taiwan typically have very diffuse and highly variable unit fluxes although the cumulative discharge can be very significant when it occurs over a wide area. Second, SGD is a process that occurs across a landsea interface that spans different scientific disciplines as well as environments. Unfortunately, there are distinct cultural and structural differences that separate terrestrial and marine scientists. Literally, hydrologists and coastal oceanographers are looking at the same problem from different ends.

For the last decade, intensive field investigations of coastal environment pollution associated with SGD are undertaken in coastal zone of Taiwan including its southwestern part (Figure 1). In [11], it was found out that aquifers are significant sources of trace elements and other chemical constituents to the southwestern coastal waters of Taiwan where onland chemicals as $\mathrm{NH}_{4}, \mathrm{SO}_{4}$, $\mathrm{NO}_{3}, \mathrm{PO}_{4}$ and $\mathrm{SiO}_{2}$, hydrocarbons, trace metals $(\mathrm{Ni}, \mathrm{Cu}$, $\mathrm{Cd}), \mathrm{NaOH}$, fertilizers, and sewage were. Reference [11] also reported the exploratory discovery of SGD by using salinity in Taiwan for the first time in the coastal area and point out that SGD may occur near the Kaoping River estuary. Recently $[12,13]$ have shown that submarine groundwaters are also clearly indicated by tracers of oxygen, strontium isotopes and barium content. They noted that the concentration of many contaminants in groundwater is typically several times higher than in seawater. Usually with distance from seepage the concentration of contaminants decreased rapidly. As observations of nitrate $\left(\mathrm{NO}_{3}\right)$ plumes near shallow seepages by $[7,14]$ shows, the flux of nitrate towards the marine environment was highly variable even over a short distance from the coast. In addition, greater dispersion near the seepage face due to movement of water masses in response of tides and to seasonal cycles of recharge to the fresh aquifer. Outside an aquifer, nitrate diminished substantially in concentration so that horizontal and vertical sizes of a detectable inclined nitrate plume did not exceed 6 and $4 \mathrm{~m}$, respectively [7].

In the coastal ocean, processes of spreading and fate of contaminants coming from SG aquifers are governed by ocean dynamics and depend on many factors as seepage zone, discharge rate and type of contaminants. Mathematically, predicting such processes is very a compli- cated task that requires developing numerical models for reproducing/predicting the ocean circulation and transport of contaminants. Until now, numerical modeling directed to the solution of problems associated with pollution inputs from SGD is mostly focused on modeling the transport and biogeochemical processes $[9,15,16]$ inside aquifers. Some works have been dedicated to analysis and modeling an influence of tides on oscillation of groundwater discharge rate $[2,17,18]$. By theoretical model for SGD and the associated chemical transfer to the ocean, [2] have demonstrated that wave setup and tidal pumping may be the processes largely responsible for the high rate of SDG and, in turn, a considerable intensification of the transport of chemicals to the ocean. Despite wide spectra of models and approaches that were built for the solution of various problems associated with contamination of coastal zone due to SDGs, yet, no attempt has been made on the development of a complex approach for predicting the regional circulation and its effect on the transport and mixing of pollutants coming into seawater from submarine seepages. Therefore the objective of this work is to fill this gap and develop a pollution transport model coupled with an ocean circulation model. In the work, we will focus on the shelf zone of the southwestern Taiwan, however, based on the generalized approach, the model can be adapted easily for any region of interest.

The paper is structured as follows: In Section 2, a short description of region of interest, hydrology and characteristics of SG based on field observations are given. In Section 3, the coupled circulation/particle-tracking model is introduced. In Section 4, results numerical experiments with conservative and nonconservative (nitrate) tracers under wind and tidal forcings as well as discussion are presented. Summary is given in Section 5.

\section{Study Region}

Figure 1 shows the coastal zone of the southwestern Taiwan. The marine environment in this area is rather unique in terms of geomorphology. A major feature the latter is Gaoping (submarine) Canyon, belonging to the river extension type canyon, and Siaoliuciou Island. The canyon is well aligned with the Gaoping River on land, runs across the continental shelf, continues its course southwestward onto the continental slope, and terminates at a depth of about $3000 \mathrm{~m}$. The head of the canyon, cutting the continental shelf, is characterized by high and steep walls, and the cross-sectional morphology of the canyon varies from $\mathrm{V}$-shaped to broadly U-shaped [19]. As field observations exhibited $[19,20]$, such peculiarities in geomorphology have a great effect on coastal circulation and mixing processes.

Complex hydrographic study of submarine groundwa- 
ter discharge in the Pingtung coastal zone [12,13] allowed finding seepage locations by tracing oxygen, strontium isotopes. Areas with notable $\mathrm{SGD}^{1}$ were found to locate a long distance from the shoreline $(\sim 25 \mathrm{~km})$ and likely to be widespread off southwestern Taiwan.

To detect shallow SGDs, quantify their rate and influence on the local hydrology as well as define the content of contaminants, the joint oceanographic observations were conducted by Taiwanese and the Russian scientific groups in February and October 2009 on the Pingtung shelf [21]. Figure 1 schematically depicts the transections of the polygon where hydrophysical and hydrochemical observations have been conducted. The solid circles depicted along the transections denote location of hydrographical stations conducted during both expeditions.

Distinct manifestations of submarine groundwater discharge were revealed near-shore, west of the Siaoliuciou Island at stations 11 and 16 (Figure 1). In the vicinity of the SG seepage (marked by solid squared in Figure 1), CTD measurements revealed salinity inversions on profiles in the $2 \mathrm{~m}$ bottom layer (Figure 2(b)), where the magnitude of the salinity drop reached $0.06 \mathrm{psu}$. For such salinity drop, the SGD rate, as was estimated by [21], should be in range between 0.1 and $1 \mathrm{gm}^{-2} \cdot \mathrm{s}^{-1}$. The estimation was based on the advection-diffusion balance of salinity in the water column affected groundwater inflow, $w S=K_{z} \mathrm{~d} S / \mathrm{d} z$, where $S$ is salinity, $z$ is vertical coordinate, $w$ is mean vertical velocity of groundwater seepage and $K_{z}$ is the eddy diffusivity.

Assuming that salinity difference, $\Delta S$, in the bottom inverse layer, $\Delta H$, significantly less than mean salinity in the bottom ambient water, $S_{0}$, i.e., $\Delta S \square S_{0}$, we obtain the velocity $w=K_{z} S_{0}^{-1} \Delta S(\Delta H)^{-1}$ and SGD rate per unit area, $Q=w \rho$, where $\rho$ is mean density. Taking average values $S_{0}=30 \mathrm{psu}, K_{z}=10^{-4} \mathrm{~m}^{2} \cdot \mathrm{s}^{-1}$ and $\rho=$ $1025 \mathrm{~kg} \cdot \mathrm{m}^{-3}$, for $\Delta S=0.06$ and $\Delta H=2 \mathrm{~m}$, we obtain $w=0.864 \mathrm{~cm} \cdot$ day $^{-1}$ and $Q=1.025 \mathrm{~g} \cdot \mathrm{m}^{-2} \cdot \mathrm{s}^{-1}$.

The deviation of vertical velocity and magnitude of the SGD rate, obtained by [21], is associated with variations of $\Delta S$ and $\Delta H$ estimated from field experiments. Besides uncertainties in estimation of $\Delta S$ and $\Delta H$ the rate, $Q$, depends on vertical diffusivity, $K_{z}$, which was chosen from general assumptions. Actually, $K_{z}$ can significantly vary in the bottom boundary layer and thus the estimates of $w$ and $Q$ can be considered as an order of magnitudes. Nevertheless they agree with the characteristic values reported earlier for well-developed SGD at other locations in the ocean [22].

The field observations also revealed that the salinity inversions coincided with maxima of dissolved oxygen, organic matter content, iron and phosphorus concentra-

\footnotetext{
${ }^{1}$ Note that SGD can be submerged springs or point sources and often are diffuse across large areas in the ocean.
}

tions, and the minimum of turbidity. Note that, in nonimpacted by SGD areas, ambient waters were characterized by regular salinity profiles with the maximum of salinity at the bottom (Figure 2(a)).

Many studies show that SGD makes a significant contribution to nutrient budget of coastal water that causes significant research interest in this phenomenon $[6,12,18]$. We made chemical analyses of water samples collected from the bottom layer of the ocean, as well as the nearshore land groundwater well (marked by solid square in Figure 1) and Kaoping River in February 2009. The results for nitrate, $\mathrm{NO}_{3}$, which we focus on, are depicted in Table 1.

As seen, measurements conducted at stations 1, 6, 11, 16 and near the SG well revealed that nitrate concentrations were higher than those at other stations not affected by SGD. This difference in $\mathrm{NO}_{3}$ concentrations appears to be consistent with the figures reported by [8] for the same area. Note that the increasing concentrations of $\mathrm{NO}_{3}$ observed at stations \#11 and \#16 cannot be explained by the river inputs, because the nitrate content in Kaoping River water was considerably lower. Above the SG well, the nitrate concentration reached $0.48 \mathrm{mg} \cdot \mathrm{L}^{-1}$ that significantly exceeded that in seawater.

Current velocity measurements conducted near by the SG well (Figure 1) indicated that along- and cross-shore components of the velocity exhibited a superposition of about $0.1 \mathrm{~m} \cdot \mathrm{s}^{-1}$ amplitude of the tidal and background northwestward coastal current of about $0.25 \mathrm{~m} \cdot \mathrm{s}^{-1}$.

\section{Coupled Model Description}

Modeling the transport and dispersal of contaminantcontaining fresh groundwater from a coastal aquifer into

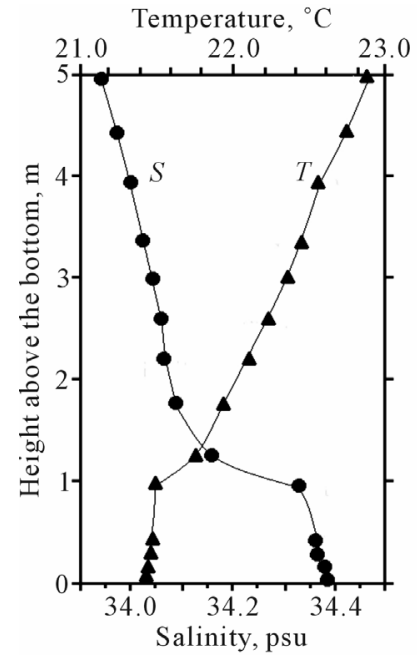

(a)

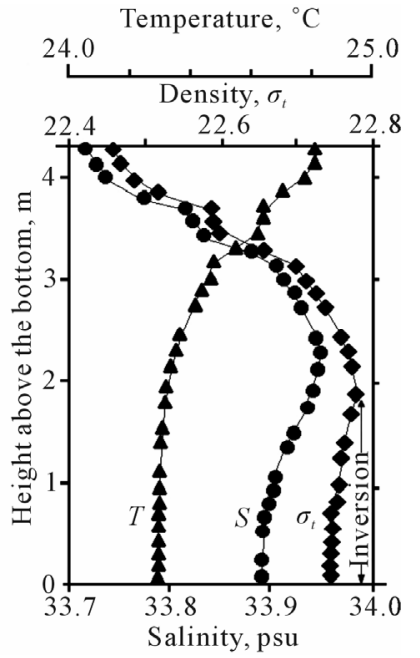

(b)
Figure 2. Typical temperature, T, and salinity, S, profiles obtained in the 5-m layer (a) far from the seepage (at station 15) and (b) those obtained near the seepage (after [21]). 
Table 1. Chemical indicators of the water samples collected from the bottom layer of the ocean, groundwater well, and Kaoping River in February, 2009. Bold values indicate SGD impacted seawater (after [21]).

\begin{tabular}{|c|c|c|}
\hline Station \# & Distance, km & Nitrate, $\mathbf{m g} \cdot \mathrm{L}^{-1}$ \\
\hline 1 & 0.5 & 0.04 \\
\hline 2 & 1.7 & 0.03 \\
\hline 5 & 1.9 & 0.04 \\
\hline 6 & 0.4 & 0.04 \\
\hline 7 & 6.8 & 0.02 \\
\hline 8 & 5.0 & 0.02 \\
\hline 9 & 2.9 & 0.02 \\
\hline 10 & 1.2 & 0.02 \\
\hline 11 & 0.3 & 0.03 \\
\hline 12 & 6.9 & 0.02 \\
\hline 13 & 5.0 & - \\
\hline 14 & 3.0 & 0.01 \\
\hline 15 & 1,3 & 0.01 \\
\hline 16 & 0.4 & 0.02 \\
\hline Average & N/A & 0.02 \\
\hline Average sites & N/A & 0.03 \\
\hline GW Well & N/A & 0.48 \\
\hline Kaoping River & N/A & 0.06 \\
\hline
\end{tabular}

the adjacent shallow marine environment presents a real challenge to oceanographers. Difficulties are associated with many factors such as the hydrostatic instability of bottom fresh water discharging into the saline environment, uncertainties of the SGD rate estimate, seepage location(s) as well as with difficulties of predicting coastal currents induced by variable forcing (wind, tides, etc.). All these factors are necessary to take into account in deciding on the choice of a particular numerical model and approach. Our approach to the solution of the transport and dispersal of contaminant-containing fresh groundwater is based on the Lagrangian particle tracking method (LPTM) that is significantly more effective than approaches based on finite-difference models since LPTM describes the advective transport with a high accuracy. This is a very important for realistic reproducing the movement a plume of contaminants. In addition, the Lagrangian method is better suited to modeling the fate and dispersal of contaminants, when the attribution of fate properties to a particular contaminant is required.

As any other similar coupled models, ours consists of a hydrodynamic model embedded into a particle transport model (PTM). PTM takes currents and turbulent diffusivities predetermined by the hydrodynamic model and uses LPTM to predict the motion of individual particles, the sum of which constitutes a contaminant plume. The basic concept of the proposed model is similar to that presented in [23-30]. Therefore, herein, we shortly discussed only those extensions/improvements of the model that are made for the present specific problem.

Generally, the procedure of predicting behavior and fate of a contaminant plume is divided into two parts: 1) predetermination of currents, turbulent diffusivities with the hydrodynamic model; and 2) applying the predetermined three-dimensional motions to individual particles, the aggregate of which constitutes the plume. The model thus simulates the advection and turbulent diffusion of particles. The physicochemical decay and processes modifying the structure and properties of a contaminant plume are simulated due to specific algorithms.

\subsection{The Hydrodynamic Module}

To predict circulation, we chose the sigma-coordinate Princeton ocean model (POM) [31] and adapted it for the southeastern part of Taiwanese coastal zone marked in Figure 1(a) by the square. The POM has a resolution of 1/60 Deg along longitude $(\Delta x)$ and latitude $(\Delta y)$. The calculation domain, $39 \times 72$ cells, covers the region of interest from $22.00^{\circ} \mathrm{N}$ to $23.05^{\circ} \mathrm{N}$ and from $120.05^{\circ} \mathrm{E}$ to $120.70^{\circ} \mathrm{E}$. Over the vertical, the model has 31 uneven $\sigma$-levels, which are distributed so that to provide the maximal resolutions near the surface and the bottom. The calculation time steps for the external, DTE, and for the internal, DTI, modes were chosen from the CFL criterion of stability [31] and equal to $6 \mathrm{~s}$ and $120 \mathrm{~s}$, respectively.

For the momentum fluxes in the near-bottom layer (1 $\left.+\sigma_{k b-1}\right) H / z_{0}$, we used the quadratic dependence on the velocity:

$$
K_{M}\left(\partial \bar{u}_{i} / \partial \sigma\right) / D=C_{z}\left[\bar{u}_{1}^{2}+\bar{u}_{2}^{2}\right]^{1 / 2}\left(\bar{u}_{i}\right)
$$

for $\sigma \rightarrow-1$, where $H(x, y)$ is depth, $D=H+\eta, \eta(x, y)$ is the elevation of the free surface, $K_{M}, z_{0}$ is the roughness parameter is the coefficient of turbulent viscosity, $u_{i}$ $(i=1,2)$ are the horizontal components of the mean current velocity, and drag coefficient, $C_{z}$ is defined as

$$
C_{z}=\max \left[\frac{\kappa^{2}}{\left[\ln \left\{\left(1+\sigma_{k b-1}\right) H / z_{0}\right\}\right]^{2}}, 0.0025\right],
$$

where $k=0.4$ is the Karman constant.

\subsubsection{Open Boundary Conditions}

At the open (western and southern) boundaries of the calculation domain, two types of boundary conditions for the temperature and salinity were used: the condition for the inflow and that for the outflow. In the case of the outflow outside the calculation domain, the values for $T$ 
and $S$ at the corresponding open boundary were setup. In the case of the inflow into the calculation domain, the radiation equation $\partial(T, S) / \partial t+\bar{u}_{n} \partial(T, S) / \partial n$ was solved [25]. The index $n$, here, represents the coordinate normal to the open boundary. The components of the mean current and the turbulent diffusivities were output to the particle transport model at every time step during the simulations.

\subsubsection{Forcing}

Two types of forcing were applied for modeling: winds and tides. For the wind forcing, we used observations by [32] presented favorable seasonal winds. For the tidal forcing, we referred to $[19,20]$ who analyzed the ratio between amplitude of tidal oscillations of coastal currents along the southwestern Taiwan induced by the astronomical semidiurnal, $M_{2}, S_{2}$ and diurnal, $K_{1}$, and $O_{1}$ constituents. They showed that the semidiurnal, $M_{2}$, constituent was the major one in energy spectra of tidal oscillation. Thus, for the first order approximation, we can simplify tidal forcing by a use of the dominant constituent $M_{2}$ only and, for tuning the circulation module, we utilized current velocity measurements conducted by [21] near by the SGD well. We applied a radiation condition based on the long gravity-wave speed, to determine the boundary elevation and a gravity-wave radiation condition to specify the normal component of the depth-averaged current at the model open boundaries.

\subsubsection{POM Initialization}

The hydrodynamic model is spun up from rest and with temperature and salinity from the ocean climatological database [33] with adjusting $T, S$-profiles, in the water column over the SG well, to those shown in Figure 2(a).

\subsection{Particle Tracking Model}

In the Lagrangian particle tracking method, an algorithm for updating particle coordinates (Equation (1)) is the following: at every time step, particles are moved in the 3-dimensional Cartesian reference frame by an advective displacement added to a diffusive jump [23].

$$
\begin{gathered}
\left(\Delta x_{i}\right)_{j, k}=\bar{u}_{i, j} \Delta t+\left(\eta_{i}\right)_{j, k} \\
\left(i=1-3 ; j=1,2, \cdots, N_{t} ; k=1,2, \cdots, N_{p}\right)
\end{gathered}
$$

The displacements, $\left(\Delta x_{i}\right)_{j, k}$, are defined as sum of a deterministic displacement caused by mean velocities, $\bar{u}_{i, j}$, and a random displacement, $\left(\eta_{i}\right)_{j, k}$, due to fluctuations of velocity. Here $N_{t}$ is the number of time steps, $\Delta t$ is the time step and $N_{p}$ is the total of particles released during a numerical experiment.

The advective movement within a grid cell is determined by linear interpolation of the velocity values from the 8 nodes of the grid cell, and computation of the displacement vector is a product of the interpolated velocity vector and the time step $\Delta t$. Diffusive jumps of particles (random displacement due to sub-grid fluctuations of velocity) along horizontal $(i=1,2)$ and vertical $(i=3)$ axes are determined differently. For the horizontal axes, we used so-called "naïve random walk" (NRW) scheme, i.e., $\eta_{i}=\gamma_{i}\left(2 K_{i, j} \Delta t\right)^{1 / 2}$ to simulate diffusive jumps. The random vector, $\gamma_{i}$, normally distributed with an averaged value of zero and unit standard deviation is converted later to yield the Gaussian distribution with zero mean and unit standard deviation. Coefficients $K_{i, j}$ represent time dependent diffusivities along the $i$-axis. Such simple scheme for the lateral transport and dispersal of particles is feasible due to a weak variation of horizontal diffusivities, $K_{i, j}$, along the correspondent axes.

Unlike $K_{i, j}$, profiles of the vertical diffusivity, $K_{3, j}$, usually exhibits significant variations in coastal waters where current and density structures are formed under tidal and wind-driven circulation and, often, under strong influence of freshwater input [29]. Such combined forcing leads to the formation of non-uniform vertical diffusivity profiles that, in case of the use of the NRW scheme, can form artificial particle accumulation zones in layers with weak vertical mixing. To avoid this effect we employed so-called a "consistent random walk" (CRW) approach $[29,34,35]$ in order to obtain vertical particle displacements correctly. For this, we applied the formula $\eta_{3}=K_{3}^{\prime}(z) \Delta t+\gamma_{3}\left[2 K_{3}\left(z^{*}\right) \Delta t\right]^{1 / 2}$, adopted from [35]. As seen, this formula includes deterministic and diffusive (or random) components. The deterministic component causes a net displacement of the center of mass of the neutrally buoyant particles toward increasing diffusivity at a rate $K_{3}^{\prime}$ (a local gradient of $K_{3}$ in the vertical direction), thus allowing avoidance of the artificial particle accumulation within layers of low vertical diffusivity. The diffusion coefficient $K$ in the CRW model is estimated from the diffusivity profile at a vertical coordinate $z^{*}$ shifted from the particle coordinate $z$ by a small distance $0.5 K_{3}^{\prime} \Delta t$. Note that the CRW model should be used for simulating horizontal displacements too. However, according to our assessment, the largest horizontal diffusivity gradient, in the coastal zone studied, is the order of $10^{-3} \mathrm{~m} \cdot \mathrm{s}^{-1}$ (cf. $K_{3 \max }^{\prime} \approx 10^{-1} \mathrm{~m} \cdot \mathrm{s}^{-1}$ ) so that the effect of $K_{1,2}^{\prime}$ on horizontal distribution of particles is negligible for a given model grid spacing and time step (see below).

As was mentioned about, the horizontal and vertical diffusion coefficients, $K_{1,2}=K_{H}$ and $K_{3}=K_{V}$ as well as the mean current velocity components, $\bar{u}_{i, j}(x, y, z, t)$, and density, $\rho(x, y, z, t)$, are provided by the POM. The horizontal diffusivities are computed with a use of Smagorinsky formula and the vertical diffusivity is obtained 
from the level-2.5 turbulence closure scheme [36]. Thus, 3-dimensional parameters available from the POM are used as forcing in the particle tracking model, which estimates particle coordinates at every time step $\Delta t$ that can be equal to (or longer than) the internal time step, DTI, of POM. The time steps is chosen to be $360 \mathrm{~s}$ that is long enough but prevents particle jumping more that one grid cell, and, thus, guarantees an accurate estimate of particle displacement in each of 3 directions.

It should be noted that, based on the random walk concept, particle tracking models coupled with the hydrodynamic models have certain structural features associated with the ratio between model time step, DTI $(\Delta t)$, and the Lagrangian timescale, $T_{\text {Lag }}$. For the vertical motion, the external timescale for smallscale turbulence in the ocean, $T_{\text {turb }}$, is of the order $1-10 \mathrm{sec}$, so that $\Delta t \geq$ $D T I \square T_{\text {turb }}$. It means that vertical velocity fluctuations and displacements of a Lagrangian particle at the time lag $\Delta t$ are not correlated we can use Equation (1) for predicting vertical $(i=3)$ particle coordinates. In contrast, for horizontal currents in the ocean, the typical value of the Lagrangian timescale $T_{\text {Lag }}$ is 1 - 3 days, so that $\Delta t \square T_{\text {lag }}$ and the random horizontal velocities and displacements of a Lagrangian particle within the time lag $\Delta t$ are correlated. For this reason, the horizontal motion $(i=1,2)$ of the particle is described by equations

$$
\begin{gathered}
\bar{u}_{i, j+1}=\bar{u}_{i, j}\left(1-\Delta t / T_{\text {lag }}\right)+\sigma_{a} A_{i} \Delta t, \\
x_{i, j+1}=x_{i, j}+\bar{u}_{i}\left(x_{i, j}, z_{i}\right) \Delta t+\left(\bar{u}_{i, j+1}+\bar{u}_{i, j}\right) \Delta t / 2,
\end{gathered}
$$

where $\sigma_{a}$ is the root mean square random acceleration, $A_{i}$ is the normally distributed random vector value with zero mean and unit variance, $x_{i, j}$ and $x_{i, j+1}$ are the horizontal radius-vector of the particle at moments $t$ and $t+\Delta t$, respectively. Note that (2) is a finite difference analogue of the Langevin equation. Note that, from POM, we have explicitly only one parameter to describe horizontal random motion of a Lagrangian particle, namely the horizontal diffusivity, $K_{H}$, while Equations (2) and (3) include two parameters, $T_{\operatorname{Lag}}$ and $\sigma_{a}$. However, taking into account that POM uses the Smagorinsky formula for the horizontal diffusivity, $K_{H}$ :

$$
\begin{aligned}
K_{H}= & C_{H} \Delta x \Delta y\left[\left(\partial \bar{u}_{1} / \partial x_{1}\right)^{2}\right. \\
& \left.+0.5\left(\partial \bar{u}_{1} / \partial x_{1}+\partial \bar{u}_{2} / \partial x_{2}\right)^{2}+\left(\partial \bar{u}_{2} / \partial x_{2}\right)^{2}\right]^{1 / 2}
\end{aligned}
$$

where $C_{H}$ is a constant, we can infer the Lagrangian timescale as $T_{\text {Lag }}=\Delta x \Delta y / K_{H}$ and the random acceleration as $\sigma_{a}=\left(2\left(K_{H}\right)^{3} / \Delta t\right)^{1 / 2} / \Delta x \Delta y \quad[26]$ and thus close the system of Equations (2) and (3).

\subsubsection{Definition of the Source}

A very important step for the model setup is to set cor- rectly the near-seepage zone processes and the discharge rate of contaminant-rich SG. Submarine groundwater coming into the seawater from coastal aquifers carries dissolved contaminants, type and properties of which depend on regional factors. Contaminants may be considered as passive and either conservative or nonconservative tracers but, being dissolved in fresh groundwater, such tracers would have vertical velocity due to the buoyancy force. The magnitude of the rise velocity depends on difference between densities of fresh SG and adjacent saline water.

In the particle tracking approach applied, we presume that submarine groundwater discharging from an aquifer breaks up into fresh water droplets with diameter, $d$, defined by empirical formula [27]

$$
d=9.52 v^{2 / 3} /\left(g^{2 / 3}\left(1-\rho_{0} / \rho\right)^{1 / 3}\right),
$$

where $\rho_{0}$ is density of SG droplets, $\rho$ and $v$ is density and viscosity of ambient water, respectively and $g$ is the acceleration of gravity. The rise velocity of the freshwater droplet can be estimated as $w=\left[8 g d\left(1-\rho_{0} / \rho\right) / 3\right]^{1 / 2}$. Thus, the magnitude of rise velocity grows with the droplet diameter and the ratio $\rho_{0} / \rho$. For $d=1 \mathrm{~mm}$, the rise velocity is about $0.25 \mathrm{~m} \cdot \mathrm{s}^{-1}$ and thus in shallow waters $(\sim 30 \mathrm{~m})$, SG droplets may appear at the sea surface in a several minutes after their release.

In the work, we applied a "stationary" source of particles, i.e., a certain number of "particles-in-SGW" (cluster), $N_{j}$, was released every $\Delta t$ seconds at the position $\left(X_{0}, Y_{0}\right)$ of seepage at the bottom. Amount of particles in a cluster $N_{j}$ is set to prescribe the initial concentration $C_{0}=\left(N_{j} / \Delta V_{0}\right)$ in the cell-volume $\Delta V_{0}=\Delta x \Delta y \Delta z$.

Two types of particles were used in numerical experiments: 1) Conservative particles that mimicked "long-live" tracers or contaminants $\left(\right.$ as $\left.{ }^{222} \mathrm{Rn},{ }^{226} \mathrm{Ra},{ }^{3} \mathrm{H},{ }^{4} \mathrm{He}\right)$ without significant attenuation in their concentration due to physico-chemical reactions; and 2) Nonconservative particles that emulate "short-live" contaminants experiencing a relatively rapid decay in result of their own properties and reactions. As an example of a nonconservative contaminant we will take nitrate $\left(\mathrm{NO}_{3}\right)$ that, as recognized now, is the major contaminant of SG. Recalling measurements by [21] discussed above, we can set the initial concentration of nitrate as $C_{0}=0.48 \mathrm{mg} \cdot \mathrm{L}^{-1}$ ), The reduction of nitrate due to denitrification and other reactions can be described by a first-order degradation process with an exponential decrease in concentration $C=C_{0} \exp (-\ln 2 / \lambda)$, where $\lambda$ is "half-life" parameter. In the particle tracking approach, effects of degradation can be treated in a similar way as radioactive decay using e-folding times $T_{e}=1 / \lambda[23,25]$ for the probability of removal of particle in a time step. According to research by [37] the process of denitrification in seawater spans 
about 100 hours and thus, in the model, we can set $T_{e}$ to be $30 \mathrm{~h}$ and use procedure of randomize half-life parameter as was described in [25].

\subsubsection{Particle Release}

To simulate a continuous source, particles are launched every DTI (180 s) time step. Coordinates of the source were chosen at the site of SG well (Figure 1) where depth was about $32 \mathrm{~m}$. In numerical experiments with conservative particles, we launched total $10^{5}$ particles every $\Delta t=D T I$ and obtained concentration in conventional units. In experiments with nitrate, every time step, we launched 15,480 particles to fit to the initial concentration of $0.48 \mathrm{mg} \cdot \mathrm{L}^{-1}$ as was obtain in the observations [21]. We limited our simulation by short-term effects of simulated currents on the development of particle plumes. Therefore in numerical experiments with wind forcing, duration of simulations was chosen to be 24 hours while simulations with tidal forcing last up to 72 hours to study behavior of nitrate plume in tidal current and the effect of nitrate degradation.

\section{Results and Discussion}

Dynamics of shallow water of the region of interest is very complicated and exhibits nonlinear effects of tidal

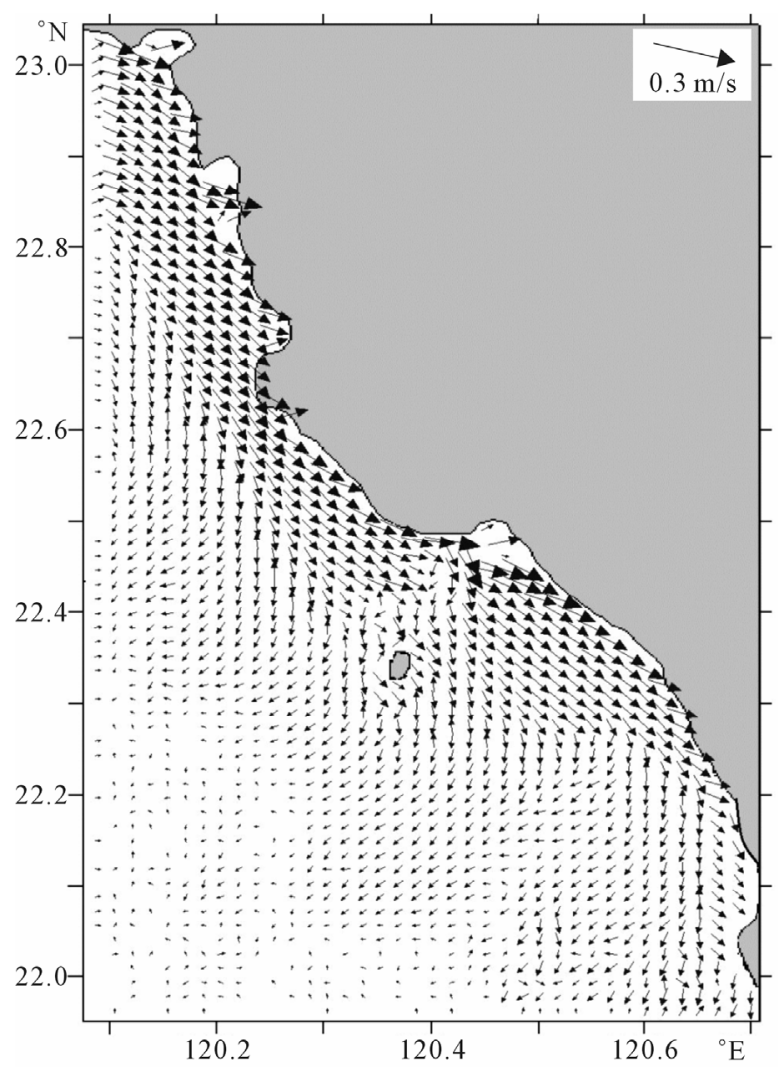

(a) and wind-induced currents [19,20,32]. In order to illustrate the ability of the proposed model, we simplified our simulation considering the effect of winds and tides separately. We run the model with two types of particles to mimicking conservative and nonconservative contaminants as was discussed above. In the first case, we simulate a wind-induced circulation forced by two favorable for autumn and summer winds. In the second one, we simulate a tidal circulation to scrutinize its effect on the nitrate plume.

\subsection{Transport of Contaminants under Wind-Induced Circulations}

\subsubsection{NNE Wind}

To scrutinize the transport and dispersal of passive conservative tracers discharged by a SG well, we forced the hydrodynamic model with the north-northeasterly (NNE) wind favorable for autumn [32]. For simplicity, we set constant wind speed with magnitude of $8 \mathrm{~m} \cdot \mathrm{s}^{-1}$. Figure 3 shows the computed near-shore circulation at the sea surface and depth of $30 \mathrm{~m}$. As seen, the NNE wind induced jet-like currents along the coast and eddy structures over the Gaoping Canyon. The wind-induced SSE current impinging on the Siaoliuciou Island created the circulation around the Island that is clearly seen at $30 \mathrm{~m}$.

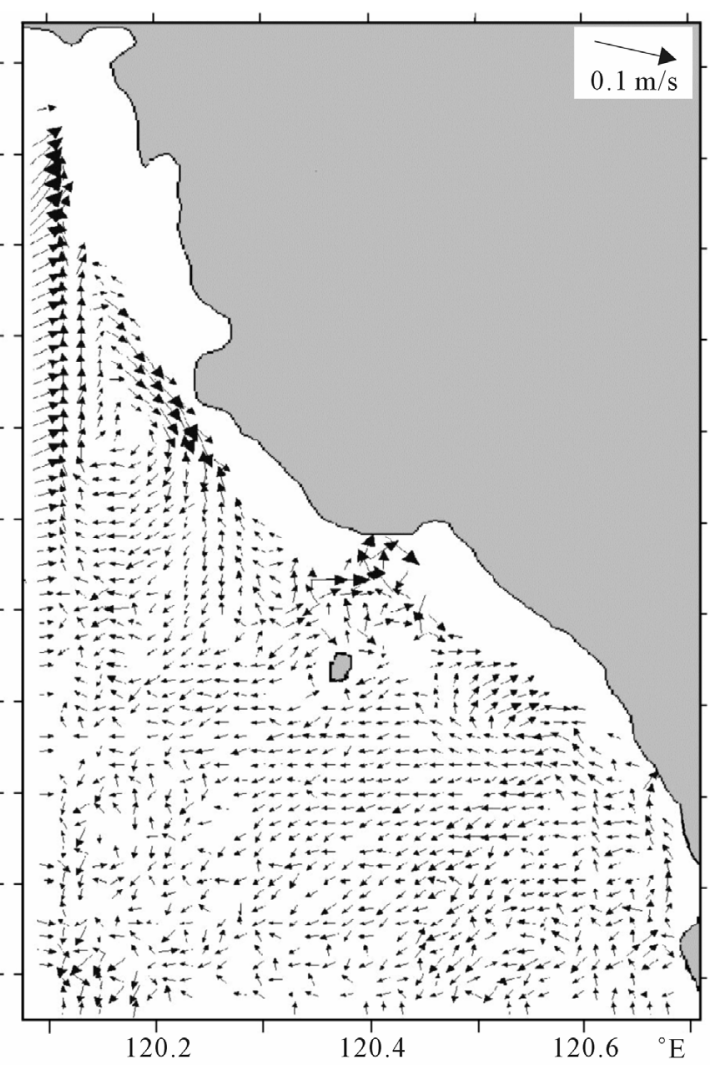

(b)

Figure 3. Examples of computed velocity at (a) the sea surface and at (b) $30 \mathrm{~m}$ under predominant $\mathrm{NNE}$ wind of $8 \mathrm{~m} \cdot \mathrm{s}^{-1}$. 
At the surface, current velocity magnitude reached 0.3 $\mathrm{m} \cdot \mathrm{s}^{-1}$ while at $30 \mathrm{~m}$ the magnitude was about $0.1 \mathrm{~m} \cdot \mathrm{s}^{-1}$. At $30 \mathrm{~m}$, the circulation revealed distinct onshore flow at the easternmost end of the Gaoping Canyon. Velocity profiles (not shown here) indicated a veering of velocity throughout the water column near the site of interest.

Figure 4 presents a planar plot of the integral ${ }^{2}$ concentration, $C(x, y)_{H}$, of particles in 24 hours after their release. Under NNE wind, the particles moved to southeast along the coast, although some particles, as seen, moved side- and backward due to the inhomogeneous structure of the current velocity. Length and width of the integral plume were about 15 and $7 \mathrm{~km}$, respectively. There were two maxima of concentration indicated the slope of the particle plume that is clearly seen in Figure 5.

Presented in Figure 5, the 2-D cumulative X-Z and $\mathrm{Y}-\mathrm{Z}$ transections of the concentration give characteristic details of vertical structure of the particle plume formed in $24 \mathrm{~h}$ after their release. Here, "cumulative" means a sum of all particles swept by the X-Z (Y-Z) area moving along the $\mathrm{Y}(\mathrm{X})$ axis.

The asymmetric vertical structure of the plume was associated with shear effects of wind-induced currents on the vertical transport and dispersal of rising particles.

\subsubsection{SSE Wind}

The second numerical experiment was performed under summer favorable wind, which, according to [32], blows from south-southeast (SSE). Similarly to the previous experiment, wind speed was chosen to be of $8 \mathrm{~m} / \mathrm{s}$.

As seen in Figure 6, the SSE wind induced strong jet-like currents at the sea surface (cf. Figure 3 ) and partly at $30 \mathrm{~m}$. A weak distortion of the surface currents occurred over the Gaoping Canyon while the strong chaotic circulation was at depth of $30 \mathrm{~m}$ indicated a significant influence of the steep structure of the Canyon on the current

Figure 7 shows the integral particle concentration distribution formed under the SSE wind of $8 \mathrm{~m} \cdot \mathrm{s}^{-1}$ in $24 \mathrm{~h}$ after their release. As seen, the area covered by particles was larger than that formed under the NNE wind; the surface plume reached the Gaoping River estuary. Length and width of the integral plume were about 17 and $8 \mathrm{~km}$, respectively. The maximum of particle concentration, as seen, was near the source location.

Figure 8 presents the $\mathrm{X}-\mathrm{Z}$ and $\mathrm{Y}-\mathrm{Z}$ transections of particle concentration. As in the experiment with SSE wind, the concentration maximum was found to be at 3 $4 \mathrm{~m}$ above the bottom indicating that the particle accumulation increased when the rise of particles was retarded. In contrast to the plume formed under NNE wind,

$\overline{{ }^{2} C(x, y)_{H}=(N / \Delta V) \text {, where } N \text {-number of particles, } \Delta V=\Delta x \cdot \Delta y \cdot H \text { and }}$ $H(x, y)$ is depth.

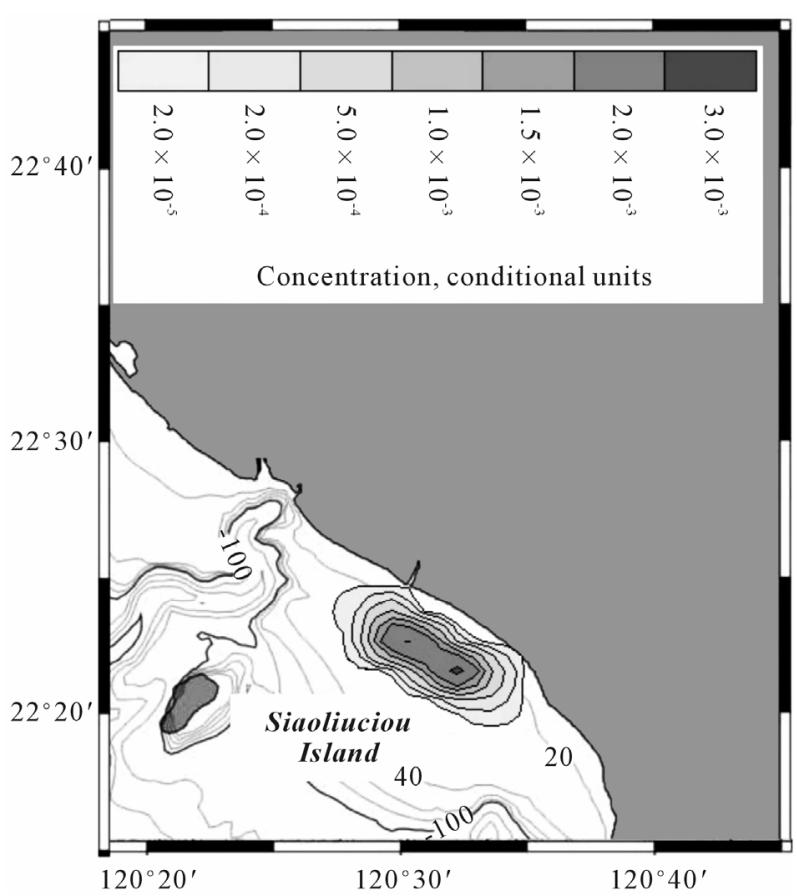

Figure 4. Integral concentrations of particles formed under NNE wind of $8 \mathrm{~m} \cdot \mathrm{s}^{-1}$ after $24 \mathrm{~h}$ of discharge.

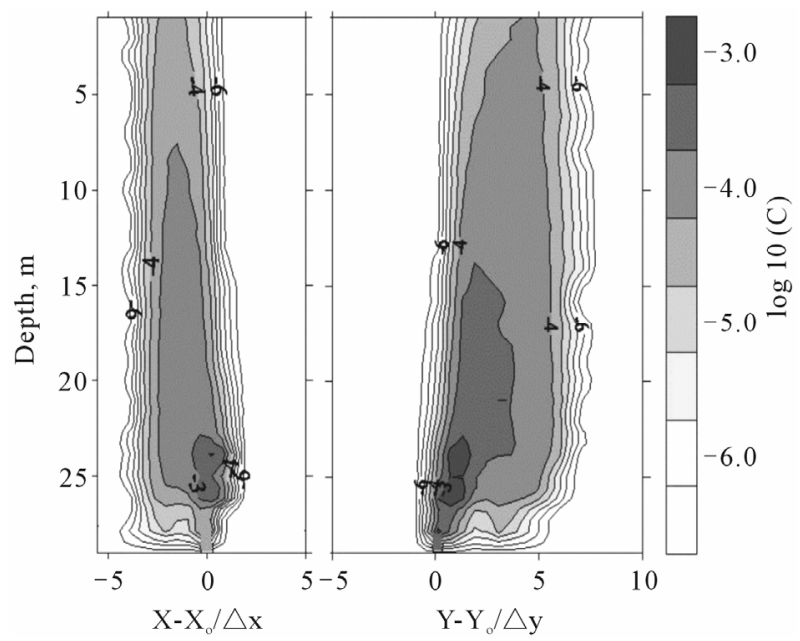

(a)

(b)

Figure 5. The $\mathrm{X}-\mathrm{Z}$ (a) and $\mathrm{Y}-\mathrm{Z}$ (b) transections through a particle plume relatively source coordinates $\left(X_{0}, Y_{0}\right)$; the experiment with NNE wind of $8 \mathrm{~m} \cdot \mathrm{s}^{-1}$.

in this case, the plume asymmetry indicated that margins with lower gradients of particle concentrations are extended to the west (negative $\mathrm{X}$ ) and to the north (positive $\mathrm{Y})$ from the source location.

\subsection{Transport and Dispersal of Nitrate in Tidal Current}

The groundwater discharging into the sea often contains nitrate with high concentrations. However, denitrification 


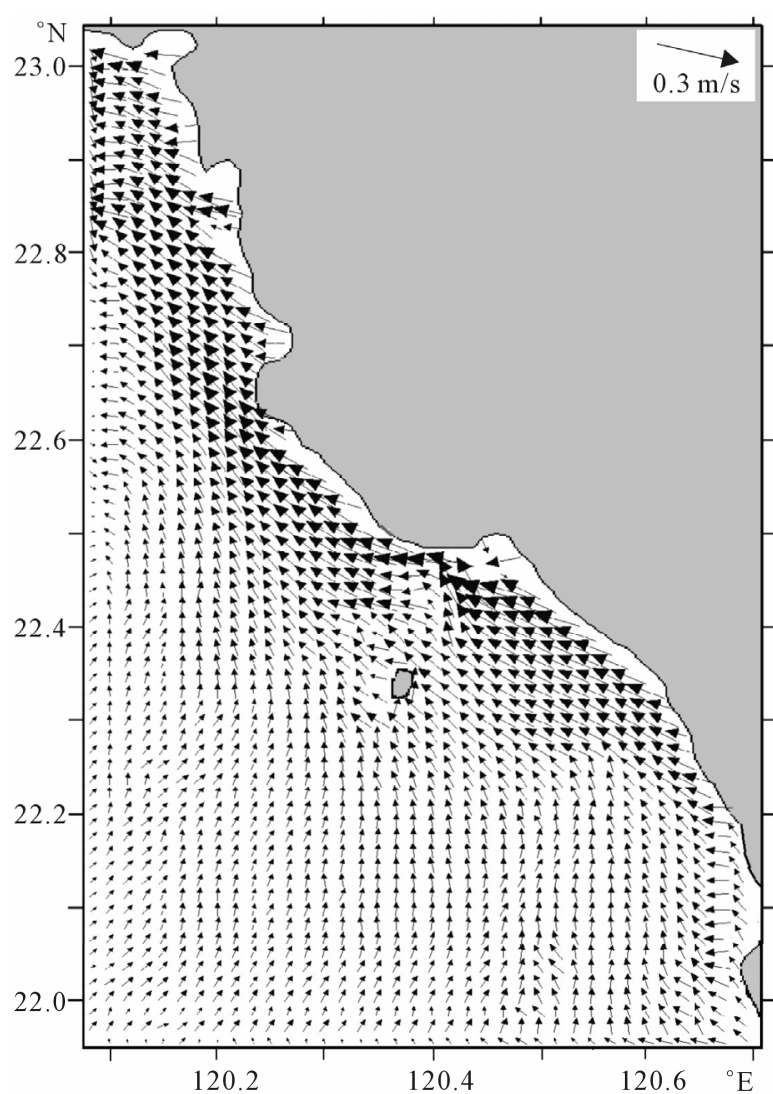

(a)

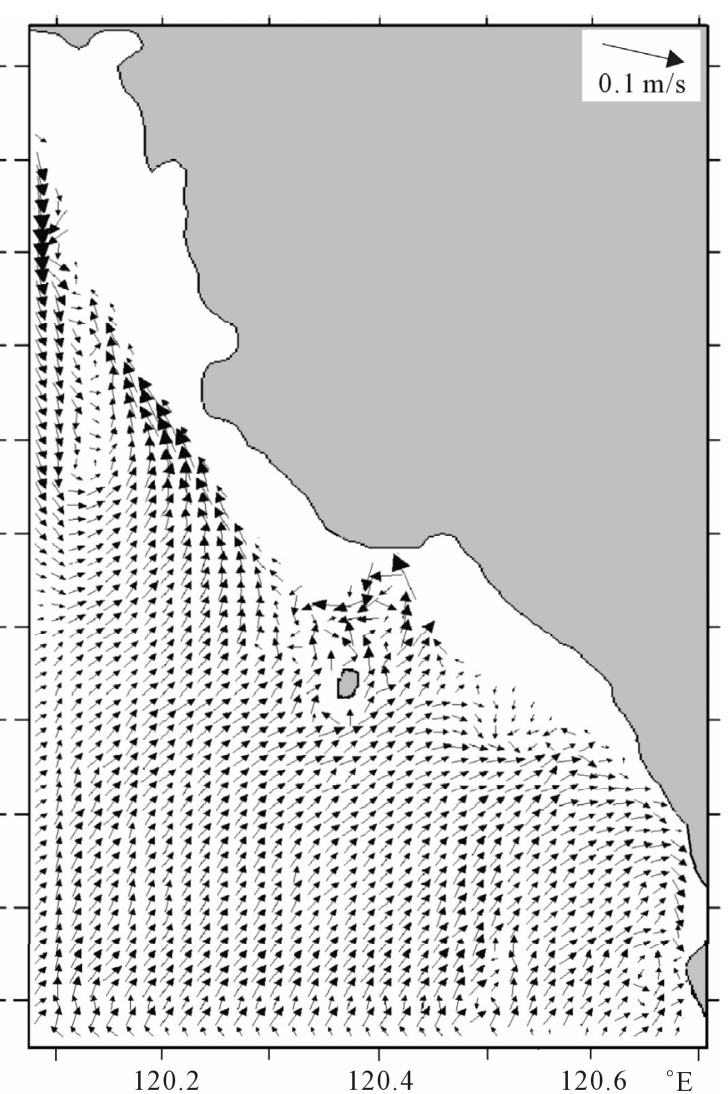

(b)

Figure 6. Examples of computed velocity at (a) the sea surface and (b) $30 \mathrm{~m}$ under predominant SSE wind of $8 \mathrm{~m} \cdot \mathrm{s}^{-1}$.

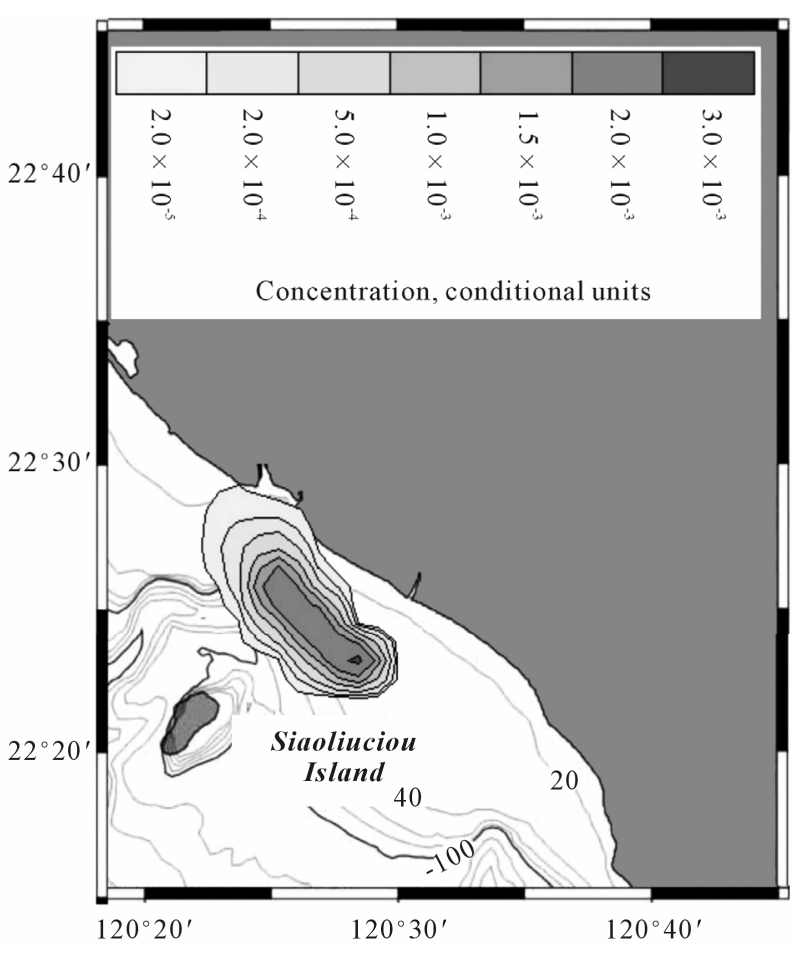

Figure 7. Integral concentration of particles formed under SSE wind of $8 \mathrm{~m} \cdot \mathrm{s}^{-1}$ after $24 \mathrm{~h}$ of discharge.

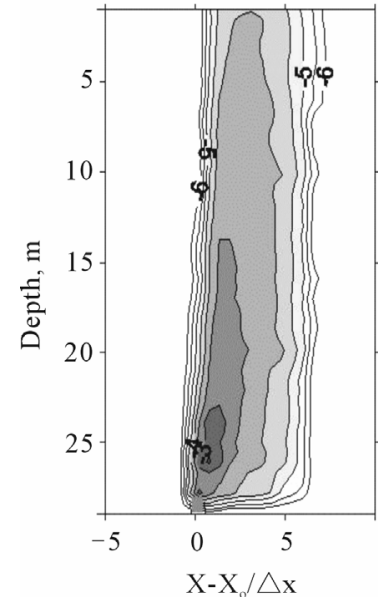

(a)

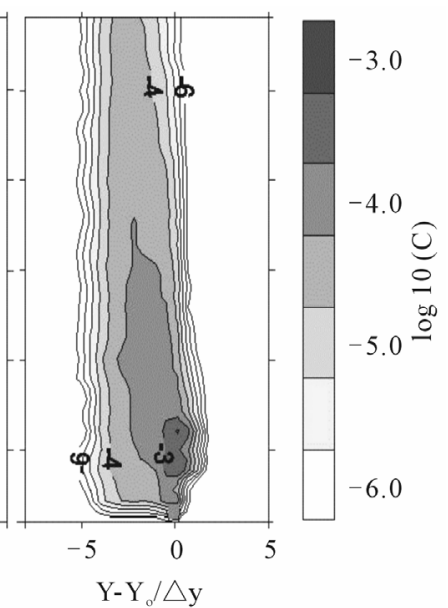

(b)
Figure 8. The $X-Z$ (a) and $Y-Z$ (b) transections through a particle plume relatively source coordinates $\left(X_{0}, Y_{0}\right)$; the experiment with SSE wind of $8 \mathrm{~m} \cdot \mathrm{s}^{-1}$.

and dilution of nitrate apparently reduces its concentration. As measurements indicated [37], the attenuation of nitrate concentration in the seawater proceeds quite rapidly. Of interest here is to estimate scales of the nitrate contamination of adjacent seawater nearby the SG well 
as well study an influence of tidal circulation on the distribution of nitrate in the impacted zone. For this, we forced the hydrodynamic model with dominant constituent $M_{2}$ and tune the model to adjust computed current velocity to that obtained in the field observations with ADCP [38].

Figure 9 presents the time series of horizontal velocity components, $U$ and $V$, and horizontal, $K_{H}$, and vertical diffusivities, $K_{V}$, at $15 \mathrm{~m}$ above the bottom. As seen, $K_{H}$ and $K_{V}$ exhibit significant variation during the tidal cycle with $K_{H}$ ranges from about 4 to $20 \mathrm{~m}^{2} \cdot \mathrm{s}^{-1}$ and $K_{V}$ ranges from about $10^{-4}$ to $10^{-2} \mathrm{~m}^{2} \cdot \mathrm{s}^{-1}$ that is very close to $K_{V}$ derived from direct measurements of turbulence obtained with a high-frequency ADCP in tidal bottom layer [38]. Minima of the viscosities lag the minima of the current velocity; the time lag is about $1.5 \mathrm{~h}$.

Figure 10 illustrates successive phases of the nitrate plume evolution in the tidal current. For the parameters of the model initialization, nitrate reached the sea surface in about $3 \mathrm{~min}$ after its release. Tidal oscillations cause to periodic variations of the plume position relatively the vertical axis. An asymmetry of current velocity and turbulent diffusivities echoes in the nitrate plume structure and variability in the water column.

As seen in Figure 10, the curvature of the plume is more pronounced when the tidal current directed to the southeast. The equalization of nitrate concentration level comes after $24 \mathrm{~h}$. Before, we see the vertical extension of the high concentration core $\left(\sim 10^{-1} \mathrm{mg} \cdot \mathrm{L}^{-1}\right)$ of the plume.

Figure 11 shows the integral nitrate concentration formed under tidal circulation in $24 \mathrm{~h}$ after nitrate release. As seen, the area occupied by particles is noticeably less than those formed in the experiments with NNE and SSE winds, and particles are mostly dispersed around the source point, through the northwestward drift is clearly seen.

\section{Summary}

Although submarine springs and seeps around Taiwan have been known for many years, these features have traditionally been perceived as hydrologic "curiosities" rather than objects for serious scientific investigation. Despite low volume (relatively the riverine input) of SGD inputs into coastal waters of the southwestern Taiwan, SGDs are recognized as potentially significant sources of various pollutants.

An assessment of SGD-originated contamination impact on ecosystems requires a complex approach to this problem including experimental study and numerical modeling. Until now, numerical modeling focused on the solution of problems associated with contaminant distribution inside aquifers and only a few works focused on the processes near-seepage zones. In the paper, we presented the 3-D coupled circulation/particle transport model for predicting coastal circulation and its effect on the transport and distribution of particles mimicking conservative and nonconservative (nitrate) contaminants discharging in seawater in result of seepage of submarine groundwater.

To our knowledge, this couple model is the first one that was developed for such specific problems. Numerical experiments were performed with favorable for autumn and summer winds and under simplified tidal circulation forced only by $M_{2}$ constituent. However, the model gave reasonable results for scales and distributions of discharged particles/contaminants in shallow zone under the applied forcing. It is worthwhile to note that

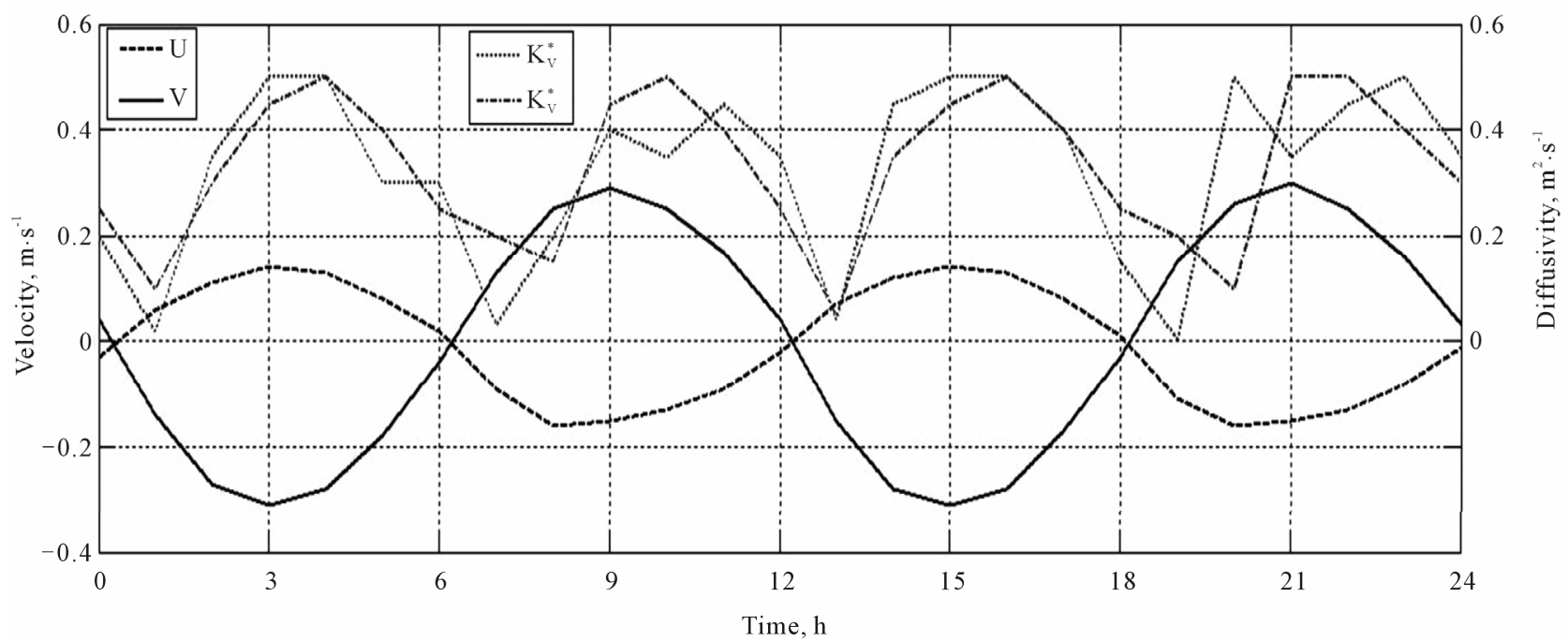

Figure 9. Tidal cycle of computed velocity components, $U$ and $V\left(\right.$ both in $\mathbf{m} \cdot \mathrm{s}^{-1}$ ), vertical $K_{V}^{*}=K_{V}^{*} 50$ and horizontal diffusivities $K_{H}^{*}=K_{H} / 40\left(\right.$ both in $\left.\mathrm{m}^{2} \cdot \mathrm{s}^{-1}\right)$ at $15 \mathrm{~m}$ above the bottom. 


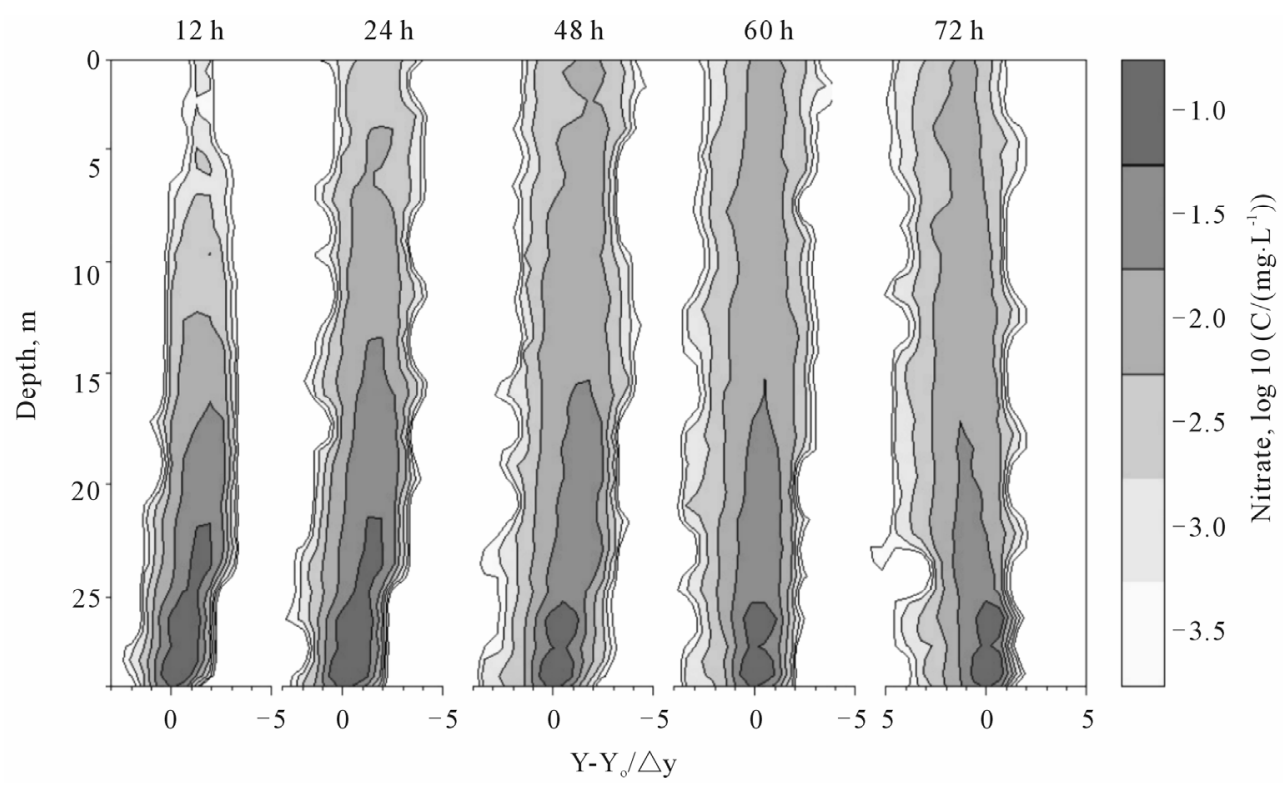

Figure 10. Successive phases of the nitrate plume (the $\mathrm{X}-\mathrm{Z}$ transection) development in tidal current. Figures in upper part of graphics indicate time after release.

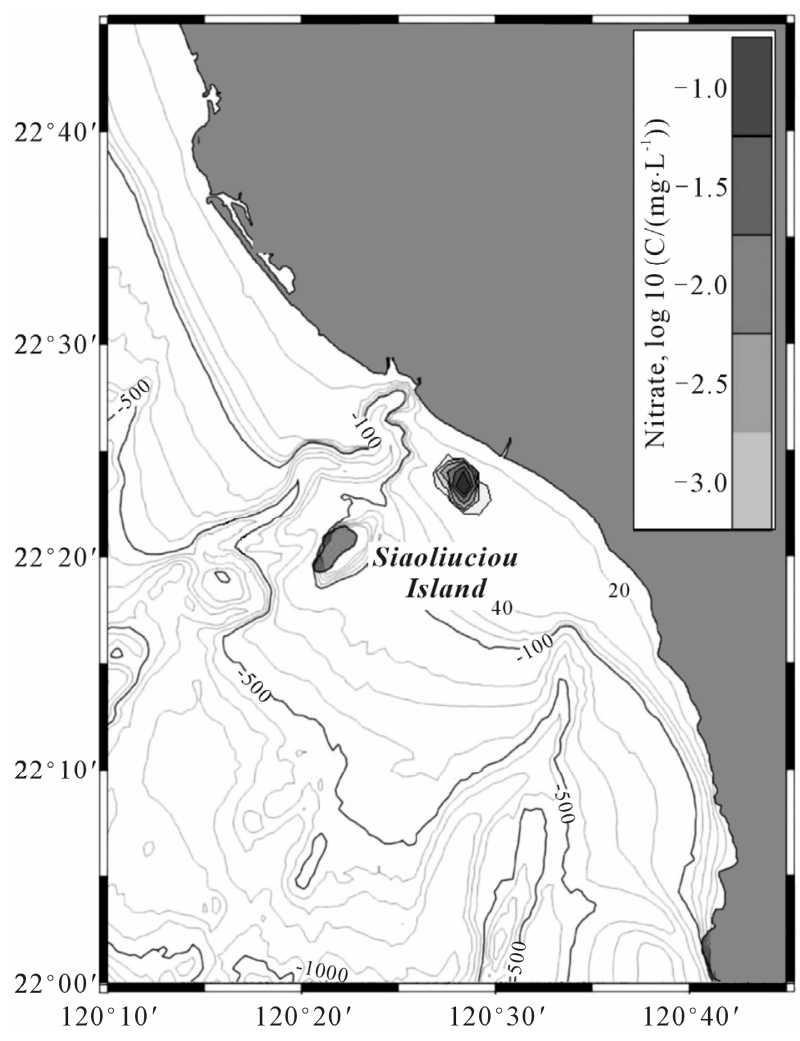

Figure 11. An integral concentration of nitrate formed by tidal circulation after $24 \mathrm{~h}$ of discharge.

despite the model was designed for Taiwanese coastal waters, but being built on general principles, it can be applied, with an appropriate adaptation, to any other regions of the ocean.

As any other model, ours requires further improve- ment that we associate with realistic forcing and initialization of the model as well as the consideration of real contaminants with their specific properties and reactions in seawater.

\section{Acknowledgements}

This work was supported by the bilateral TaiwaneseRussian Project "Monitoring, Assessment, and Management Implications of Submarine Groundwater Discharge in Taiwan" between P. P. Shirshov Institute of Oceanology, Russian Academy of Sciences, Russia, and Tainan Hydraulics Laboratory, National Cheng Kung University, Taiwan.

\section{REFERENCES}

[1] E. A. Kontar and I. S. Zektser, "Submarine Discharge and Its Effect on Oceanic Processes in the Coastal Zone," Water Resources, Vol. 26, 1999, p. 512.

[2] L. Li, D. A. Barry, F. Stagnitti and J.-Y. Parlange, "Submariane Groundwater Discharge and Associated Chemical Input to a Coastal Sea," Water Resource Research, Vol. 35, No. 11, 1999, pp. 3253-3259. doi:10.1029/1999WR900189

[3] P. K. Weiskel and B. L. Howes, "Differential Transport of Sewage-Derived Nitrogen and Phosphorus through a Coastal Watershed," Environmental Science \& Technology, Vol. 26, No. 4, 1992, pp. 352-360. doi:10.1021/es00026a017

[4] J. W. Portonoy, B. L. Nowicki, C. T. Roman and D. W. Urish, "The Discharge of Nitrate Contaminated Groundwater from Developed Shoreline to Marsh-Fringed Estuary," Water Resources Research, Vol. 34, No. 11, 1998, 
pp. 3095-3104. doi:10.1029/98WR02167

[5] B. L. Nowicki, E. Requintina, D. Vankeuren and J. Portnoy, "The Role of Sediment Denitrification in Reducing Groundwater-Derived Nitrate Inputs to Nauset Marsh Estuary, Cape Cod, Massachusetts," Estuaries and Coasts, Vol. 22, No. 2, 1999, pp. 245-259. doi:10.2307/1352981

[6] L. F. H. Niencheski, H. L. Windom, W. S. Moore and R. A. Jahnke, "Submarine Groundwater Discharge of Nutrients to the Ocean along a Coastal Lagoon Barrier, Southern Brazil," Marine Chemistry, Vol. 106, No. 3-4, 2007, pp. 546-561. doi.10.1016/j.marchem.2007.06.004

[7] K. D. Kroeger and M. A. Charette, "Nitrogen Biogeochemistry of Submarine Groundwater Discharge," Limnology Oceanography, Vol. 53, No. 3, 2008, pp. 10251039.

[8] C.-T. A. Chen and S.-L. Wang, "Carbon, Alkalinity and Nutrient Budget on the East China Sea Continental Shelf," Journal of Geophysical Research, Vol. 104, No. C9, 1999, pp. 20675-20869.

[9] C. P. Slomp and P. Van Cappellen, "Nutrient Inputs to the Coastal Ocean through Submarine Groundwater Discharge: Controls and Potential Impact," Journal of Hydrology, Vol. 295, No. 1-4, 2004, pp. 64-86. doi:10.1016/j.jhydrol.2004.02.018

[10] E. A. Kontar and W. C. Burnett, "Study of Groundwater Discharge to the Coastal Zone and Evaluation of Potential Earthquakes," Proceedings of International Conference on Marine Environment, the Past, Present and Future, National Sun Yat-sen University, Kaohsiung, 26-28 January 1999.

[11] R.-M. Wang, C.-F. You, H.-Y. Chu and J.-J. Hung, "Seasonal Variability of Dissolved Major and Trace Elements in the Gaoping (Kaoping) River Estuary, Southwestern Taiwan," Journal Marine Systyem, Vol. 76, No. 4, 2009, pp. 444-456. doi:10.1016/j.jmarsys.2007.11.012

[12] I.-T. Lin, C.-H. Wang, C.-F. You, S. Lin, K.-F. Huang and Y.-G. Chen, "Deep Submarine Groundwater Discharge Indicated by Tracers of Oxygen, Strontium Isotopes and Barium Content in the Pingtung Coastal Zone, Southern Taiwan," Marine Chemistry, Vol. 122, No. 1-4, 2010, pp. 51-58. doi:10.1016/j.marchem.2010.08.007

[13] I.-T. Lin, C.-H. Wang, S. Lin and Y.-G. Chen, "Groundwater-Seawater Interactions off the Coast of Southern Taiwan: Evidence from Environmental Isotopes," Journal of Asian Earth Sciences, Vol. 41, 2011, pp. 250-262. doi:10.1016/j.jseaes.2011.03.001

[14] M. S. Andersen, L. Baron, J. Gudbjerg, J. Gregersen, D. Chapellier, R. Jakobsen and D. Postma, "Discharge of Nitrate-Containing Groundwater into a Coastal Marine Environment," Journal of Hydrology, Vol. 336, No. 1-2, 2007, pp. 98-114. doi:10.1016/j.jhydrol.2006.12.023

[15] Y. Uchiyama, K. Nadaoka, R. P. Peter, K. Adachi and H. Yagi, "Submarine Groundwater Discharge into the Sea and Associated Nutrient Transport in a Sandy Beach," Water Resource Research, Vol. 36, No. 6, 2000, pp. 1467-1479. doi:10/1029/2000WR900029

[16] C. Spiteri, C. P. Slomp, K. Tuncay and C. Meile, "Modeling Biogeochemical Processes in Subterranean Estuar- ies: Effect of Flow Dynamics and Redox Conditions on Submarine Groundwater Discharge of Nutrients," Water Resource Research, Vol. 44, 2008, Article ID: W04701. doi:10.1029/2007WR006071

[17] C. Leote, J. S. Ibanhez and C. Rocha, "Submarine Groundwater Discharge as a Nitrogen Source to the Ria Formosa Studied with Seepage Meters," Biogeochemistry, Vol. 88, No. 2, 2008, pp. 185-194. doi:10.1007/s10533-008-9204-9

[18] R. Santos, W. C. Burnett, T. Dittmar, I. G. N. A. Suryaputra and J. Chanton, "Tidal Pumping Drives Nutrient and Dissolved Organic Matter Dynamics in a Gulf of Mexico Subterranean Estuary," Geochimica et Cosmochimica Acta, Vol. 73, No. 5, 2009, pp. 1325-1339. doi:10.1016/j.gca.2008.11.029

[19] I.-H. Lee, R.-C. Lien, J. T. Liu, W.-S. Chuang and J. Xu, "Turbulent Mixing and Internal Tides in Gaoping (Kaoping) Submarine Canyon," Journal of Marine Systems, Vol. 76, 2009, pp. 383-396. doi:10.1016/j.jmarsys.2007.12.011

[20] Y. H. Wang, I. H. Lee and J. T. Liu, "Observation of Internal Tidal Currents in the Kaoping Canyon off Southwestern Taiwan. Estuarine," Estuarine, Coastal and Shelf Science, Vol. 80, 2008, pp. 153-160. doi:10.1016/j.ecss.2008.07.016

[21] P. O. Zavialov, R.-C. Kao, V. V. Kremenetskiy, V. I. Peresypkin, C.-F. Ding, R.-T. Hsu, O. V. Kopelevich, K. A. Korotenko, Y.-S. Wu and P. Chen, "Evidence for Submarine Groundwater Discharge on the Southwestern Shelf of Taiwan," Coastal Shelf Research, Vol. 4, 2012, pp. 18-25. doi: 10.1016/j.csr.2011.11.010

[22] Intergovernmental Oceanographic Commission, "Submarine Groundwater Discharge: Management Implications, Measurements, and Effects," IOC Manuals and Guides, Vol. 44, 2004.

[23] K. A. Korotenko, R. M. Mamedov and C. N. K. Mooers, "Prediction of the Dispersal of Oil Transport in the Caspian Sea Resulting from a Continuous Release," Spill Science and Technology Bulletin, Vol. 5-6, 2001, pp. 323339. doi:10.1016/S1353-2561 (01)00050-0

[24] K. A. Korotenko, "Warfare Chemicals Dumped in the Baltic Sea: Modeling Transport Processes of Pollution Resulting from Possible Leakages," Oceanology, Vol. 43, No. 1, 2003, pp. 11-23.

[25] K. A. Korotenko, R. M. Mamedov, A. E. Kontar and L. A. Korotenko, "Particle Tracking Method in the Approach for Prediction of Oil Slick Transport in the Sea: Modelling oil Pollution Resulting from River Input," Journal of Marine Systems, Vol. 48, No. 1-4, 2004, pp. 159-170. doi:10.1016/j.jmarsys.2003.11.023

[26] K. A. Korotenko and A. V. Sentchev, "Effects of Particle Migration on the Features of Their Transport by Tidal Currents in a Region of Freshwater Influence," Oceanology, Vol. 48, No. 5, 2008, pp. 622-633. doi:10.1134/S0001437008050020

[27] K. A. Korotenko, M. J. Bowman and D. E. Dietrich, "High-Resolution Model for Predicting the Transport and Dispersal of Oil Plumes Resulting from Accidental Discharges in the Black Sea," Recent Advances in Numerical 
Ocean Modeling and Prediction, Terrestrial Atmospheric and Oceanic Sciences, Vol. 21, 2010, pp. 123-136. doi:10.3319/TAO.2009.04.24.01(IWNOP)

[28] V. Sentchev and K. A. Korotenko, "Stratification and Tidal Current Effects on Larval Transport in the Eastern English Channel: Observations and 3D Modeling," Environmental Fluid Mechanics, Vol. 4, No. 3, 2004, pp. 305-331. doi:10.1023/B:EFMC.0000024246.39646.1d

[29] V. Sentchev and K. A. Korotenko, "Dispersion Processes and Transport Pattern in the ROFI System of the Eastern English Channel Derived from a Particle-Tracking Model," Continental Shelf Research, Vol. 25, No. 16, 2005, pp. 2294-2308. doi:10.1016/j.csr.2005.09.003

[30] V. Sentchev and K. A. Korotenko, "Modeling Distribution of Flounder Larvae in the Eastern English Channel: Sensitivity to Physical Forcing and Biological Behavior," Marine Ecology Progress Series, Vol. 347, 2007, pp. 233-245. doi:10.3354/meps06981

[31] F. Blumberg and G. L. Mellor, "A Description of a Three-Dimensional Hydrodynamic Model of New York Harbor Region," Journal Hydraulic Engineering, Vol. 125, 1987, pp. 799-816.

[32] B. W. J. Kern, Y.-L. Chen and M.-Y. Chang, "The Diurnal Cycle of Winds, Rain, and Clouds over Taiwan during the Mey-Yu, Summer, and Autumn Rainfall Regimes," Monthly Weather Review, Vol. 138, No. 2, 2010, pp. 497-516. doi:10.1175/2009MWR3031.1

[33] S. Levitus, "World Ocean Atlas/NOAA Atlas," US Department of Commerce. NOAA/NODC, 2009.

[34] J. Hunter, C. Craig and H. Phillips, "On the Use of Random-Walk Models with Spatially-Variable Diffusivity," Journal of Computational Physics, Vol. 106, No. 2, 1993, pp. 366-376. doi:10.1016/S0021-9991(83)71114-9

[35] A. Visser, "Using Random Walk Models to Simulate the Vertical Distribution of Particles in a Turbulent Water Column," Marine Ecology Progress Series, Vol. 158, 1997, pp. 275-281. doi:10.3354/meps 15827

[36] G. L Mellor and T. Yamada, "Development of a Turbulence Closure Model for Geophysical Fluid Problems," Review of Geophysics Space Physics, Vol. 20, No. 4, 1982, pp. 851-875. doi:10.1029/ RG020i004p00851

[37] J. J. Coering and J. D. Cline, "A Note on Denitrification in Seawater," Limnology and Oceanography, Vol. 15, 1970, pp. 306-309.

[38] K. A. Korotenko and A. V. Sentchev, "Turbulence Investigation in a Tidal Coastal Region," Oceanology, Vol. 51, No. 3, 2011, pp. 394-406. doi:10.1134/S000143701103012X. 